\title{
Time Course Variation of Some Latex Physiological Parameters Associated with Yield of Rubber (Hevea brasiliensis) Grown in Eastern Province of Sri Lanka
}

\author{
R.G.N. Lakshman", V.H.L. Rodrigo, K.V.V.S. Kudaligama, P.I. Yapa, R.P.S. Randunu \\ Rubber Research Institute, Dartonfield, Agalawatte, Sri Lanka \\ *lakshman.rgn@gmail.com
}

\begin{abstract}
Rubber cultivation in Eastern Province, is predominantly in the intermediate zone of which climatic conditions are considered to be sub-optimal for growing rubber. Due to low level of atmospheric RH\%, latex flow tends to cease early after tapping in these areas. Turgidity of latex vessels associated with the water content of latex vessels decreases with the sunrise when evapotranspiration increases. Hence, time of commencing tapping greatly influences on the latex yield. Therefore, the present study was aimed to identify the best time of the day for latex harvesting through an assessment on latex physiological parameters.

In order to identify the best time for tapping, variations in several physiological parameters together with latex yield were assessed at different time intervals, i.e., 04:00, 05:00, 06:00, 07:00 and 08:00 in two smallholder sites in the eastern Province. Latex volume, dry rubber content (DRC\%), initial flow rate (IFR) and plugging index (PI) were analysed along with the environmental factors at the time of tapping.

Latex volume per day (LVPD) was highly associated with the overall latex yield hence had become the prime factor concerned. The highest LVPD was recorded between 05:00 to 06:00 hrs. Dry rubber content of latex had increased after 06:00 $\mathrm{h}$ and that could be attributed to the water status of the trees which was governed by evapotranspiration. During 05:00-06:00 hrs time period, $\mathrm{RH} \%$ was almost $100 \%$ and temperature was around $23^{\circ} \mathrm{C}$. When tapping commenced after 06:00 h, the overall yield declined. There was a tendency of increasing the plugging index (PI) with the delay of tapping. Therefore, the study concluded that high yields could be obtained in this agro-ecological region if tapping is performed before 06:00 $\mathrm{h}$.
\end{abstract}

Keywords: Hevea, Intermediate zone, Rubber, Sub-optimal climatic conditions, Tapping time 